\title{
Mitochondrial Dysfunction and Insulin Resistance: Topic of High Interest in Research
}

\author{
Ivan Lozada Martinez ${ }^{1 *}$, Daniela Torres Llinás ${ }^{2}$, Jaine Anaya Rivera ${ }^{2}$, Jennifer Jiménez \\ Valverde $^{2}$ and Milena Castro Berrio ${ }^{2}$
}

${ }^{1}$ Director of Medical-Surgical Research Center, School of Medicine, University of Cartagena, Cartagena Colombia

${ }^{2}$ Researcher, Medical-Surgical Research Center, School of Medicine, University of Cartagena, Cartagena, Colombia

\begin{abstract}
*Corresponding author: Ivan David Lozada Martinez, Director of Medical-Surgical Research Center, School of Medicine, University of Cartagena, Cartagena, Colombia
\end{abstract}

Insulin resistance is a condition derived from the disorder in the use of substrates for metabolic activities [1]. It can be caused by chronic hyperinsulinemia, inflammation, and long-term use of corticosteroids. In vivo and in vitro models have revealed that this process is secondary to the excessive production of mitochondrial oxidants, a product of mitochondrial dysfunction, even in cases where mitochondrial respiration is conserved [2]. Insulin increases the number of type 4 glucose transporters (GLUT4) on the cell surface, via the phosphatidylinositol 3-kinase/Akt (PI3K/Akt) signaling pathway, producing the appropriate intra-cellular glucose transport for use [3]. This process is affected in insulin resistance, becoming a potential risk factor for chronic non-communicable diseases such as type 2 Diabetes Mellitus, Obesity, Coronary Heart Disease, Non-alcoholic Fatty Liver Disease, Atherosclerosis, among many others [4].

Taking into account that these diseases have a very high global prevalence, leading to high morbidity and mortality rates, in addition to having high economic costs for therapeutic expenses, incapacitation, and disability [5]; the clinical, cellular, molecular and genetic study, has become a priority in the area of biomedical research, to find the metabolic pathways involved in these pathophysiological mechanisms, which facilitate the design of diagnostic tools and therapeutic targets, to optimize the approach and improve the survival and quality of life of these patients [6].
The relationship between mitochondrial dysfunction and insulin resistance has been a topic of research interest in the biomedical area that has grown considerably during the last decade, a product of technological advances that have made it possible to go further in cellular and molecular evaluation [7]. To the extent that it is clearly described that this pathological process is generated liver cells, skeletal muscle, brain, adipose tissue, among others [4]. In the clinical context, it is essential to know the systemic impact of insulin resistance, since it allows establishing a more accurate diagnosis and prognosis on the real situation of those individuals at risk. In those patients who have isolated insulin resistance, significant changes have been found regarding the accumulation of fatty acids in liver and muscle tissue, inflammatory markers, microbiota, epigenetic interaction, and response to endoplasmic reticulum stress [8-10]. Besides, since mitochondrial dysfunction is the product of mitochondrial defense mechanisms, which include changes in distribution, fusion, fission, and specific activation of internal pathways [11], ultimately leading to mitophagy, the decrease in the number of mitochondria, and consequently of the cellular lesion by an increase of reactive oxygen species is presumed, since there is an alteration within the system of regulation of oxidants/ antioxidants, the dysfunction is systemic $[7,12]$.

Promising studies have been made, where it has been possible to evaluate the activity of various substances

Citation: Martinez IL, Llinás DT, Rivera JA, Valverde JJ, Berrio MC (2021) Mitochondrial Dysfunction and Insulin Resistance: Topic of High Interest in Research. Int Arch Vasc Med 4:011. doi.org/10.23937/26903164/1710011

Accepted: December 04, 2021: Published: December 06, 2021

Copyright: (C) 2021 Martinez IL, et al. This is an open-access article distributed under the terms of the Creative Commons Attribution License, which permits unrestricted use, distribution, and reproduction in any medium, provided the original author and source are credited. 
against the cell lesion produced by insulin resistance, these studies show that it is possible to suppress oxidative pathways, preventing and significantly controlling damage to tissues primarily affected $[13,14]$. It is necessary to design and carry out studies of the best quality, which evaluate the effectiveness of substances related to mitochondrial and cellular protection, that promise to be therapeutic targets that not only serve for cardiometabolic diseases but, that also impact on conditions where no association has even been found.

\section{Financial Support}

None.

\section{Conflict of Interest}

None.

\section{Authors Contribution}

All authors have contributed for this manuscript.

\section{References}

1. Krycer JR, Elkington SD, Diaz-Vegas A, Cooke KC Burchfield JG, et al. (2020) Mitochondrial oxidants, but not respiration, are sensitive to glucose in adipocytes. J Biol Chem 295: 99-110.

2. Fazakerley DJ, Chaudhuri R, Yang P, Maghzal GJ, Thomas $\mathrm{KC}$, et al. (2018) Mitochondrial CoQ deficiency is a common driver of mitochondrial oxidants and insulin resistance. Elife 7: e32111.

3. Fazakerley DJ, Minard AY, Krycer JR, Thomas KC, Stöckli $\mathrm{J}$, et al. (2018) Mitochondrial oxidative stress causes insulin resistance without disrupting oxidative phosphorylation. J Biol Chem 293: 7315-7328.

4. Bonamichi BD, Parente EB, Campos AC, Cury AN, Salles JE (2017) Hyperglycemia effect on coronary disease in patients with metabolic syndrome evaluated by intracoronary ultrasonography. PLoS One 12: e0171733.

5. Mohammadbeigi A, Farahani H, Moshiri E, Sajadi $M$, Ahmadli R, et al. (2018) Prevalence of metabolic syndrome and associations with lipid profiles in Iranian men: A population-based screening program. World J Mens Health 36: $50-56$.
6. Williams AS, Koves TR, Davidson MT, Crown SB, FisherWellman KH, et al. (2020) Disruption of acetyl-lysine turnover in muscle mitochondria promotes insulin resistance and redox stress without overt respiratory dysfunction. Cell Metab 31: 131-147.

7. Su Z, Nie Y, Huang X, Zhu Y, Feng B, et al. (2019) Mitophagy in hepatic insulin resistance: Therapeutic potential and concerns. Front Pharmacol 10: 1193.

8. Crossland H, Skirrow S, Puthucheary ZA, ConstantinTeodosiu D, Greenhaff PL (2019) The impact of immobilisation and inflammation on the regulation of muscle mass and insulin resistance: Different routes to similar endpoints. J Physiol 597: 1259-1270.

9. Kikuchi K, Ben Othman M, Sakamoto K (2018) Sterilized bifidobacteria suppressed fat accumulation and blood glucose level. Biochem Biophys Res Commun 501: 10411047.

10. Vatner DF, Goedeke L, Camporez JG, Lyu K, Nasiri AR, et al. (2018) Angptl8 antisense oligonucleotide improves adipose lipid metabolism and prevents diet-induced NAFLD and hepatic insulin resistance in rodents. Diabetologia 61: 1435-1446.

11. Perreault L, Newsom SA, Strauss A, Kerege A, Kahn DE, et al. (2018) Intracellular localization of diacylglycerols and sphingolipids influences insulin sensitivity and mitochondrial function in human skeletal muscle. JCI Insight 3: e96805.

12. Ma X, McKeenT, Zhang J, Ding WX (2020) Role and mechanisms of mitophagy in liver diseases. Cells 9: 837.

13. Wang L, Zhang B, Huang F, Liu B, Xie Y (2016) Curcumin inhibits lipolysis via suppression of ER stress in adipose tissue and prevents hepatic insulin resistance. J Lipid Res 57: 1243-1255.

14. Wang J, Zou Q, Suo Y, Tan X, Yuan T, et al. (2019) Lycopene ameliorates systemic inflammation-induced synaptic dysfunction via improving insulin resistance and mitochondrial dysfunction in the liver-brain axis. Food Funct 10: 2125-2137. 